\title{
Effects of High-Frequency Bio-Oxidative Ozone Therapy in Temporomandibular Disorder-Related Pain
}

\author{
Mansur Doğan ${ }^{a}$ Derya Özdemir Doğan ${ }^{b}$ Cevdet Düger ${ }^{c}$ İclal Özdemir Kol ${ }^{c}$ \\ Aysun Akpınar ${ }^{d}$ Burcu Mutaf ${ }^{b}$ Türker Akar ${ }^{b}$ \\ Departments of a Otolaryngology, ${ }^{b}$ Prosthetic Dentistry, ${ }^{\mathrm{c}}$ Anesthesiology and Pain and ${ }^{\mathrm{d}}$ Periodontology, \\ Cumhuriyet University School of Medicine, Sivas, Turkey
}

\section{Key Words}

Ozone therapy · High-frequency bio-oxidative therapy ·

Temporomandibular disorder · Pain

\begin{abstract}
Objective: It was the aim of this study to compare the efficacy of ozone therapy and drug treatment in patients with painful temporomandibular joint (TMJ) disorder (TMD). Subjects and Methods: A total of 63 patients with TMD were enrolled; 33 were treated with bio-oxidative therapy and 30 with a ketoprofen tablet thiocolchicoside capsule $2 \times 1$ for 7 days. Maximum voluntary interincisal mouth opening (MMO) was measured in millimeters using a scale and recorded during the pre- and posttreatment periods. The patients evaluated their subjective pain using a visual analogue scale (VAS). Data were analyzed using the Mann-Whitney $\mathrm{U}$ test, the Kolmogorov-Smirnov test, and the independent $t$ test. Results: The mean MMO of the group that received ozone therapy during the pretreatment period was $46.51 \pm 8.2 \mathrm{~mm}$, and it immediately increased to $48.78 \pm 7.5 \mathrm{~mm}$ after 1 week of ozone therapy, which was statistically significant $(p=0.04)$. For those who received medication, the mean $\mathrm{MMO}$ during the pretreatment period was $46.30 \mathrm{~mm}$, and at the end of 1 week it was $46.9 \mathrm{~mm}$. In the ozone group, $29 \%$ of patients
\end{abstract}

showed a gradual decrease in their VAS pain scores compared to pretreatment values $(6.3 \pm 2.1$ to $3.0 \pm 2.2)$. In the medication group, $24 \%$ of patients showed a significant decrease in VAS pain scores during the follow-up period (6.9 \pm 1.4 to $5.0 \pm 1.5$ ). Conclusion: This study showed that bio-oxidative therapy was a more effective treatment than medication therapy for relieving TMJ pain.

(c) 2014 S. Karger AG, Basel

\section{Introduction}

Temporomandibular joint (TMJ) disorders (TMDs) are a group of conditions that result in TMJ pain, which frequently limits talking, chewing and other basic daily activities with high levels of pain-related disability [1]. The etiology of TMDs is little understood but has been associated with several factors including malocclusion, trauma, emotional stress, parafunctional habits (clenching or bruxing), synovitis, capsulitis, osteoarthritis, and internal derangement of the TMJ [2-4]. Internal de-

This study has won the best poster prize at the 19th International Congress of Aegean Region Dentists, Mugla, Turkey.

\begin{tabular}{ll}
\hline KARGER & $\begin{array}{l}\text { @ 2014 S. Karger AG, Basel } \\
1011-7571 / 14 / 0236-0507 \$ 39.50 / 0 \quad \text { Karger }\end{array}$ \\
E-Mail karger@karger.com & $\begin{array}{l}\text { Thisis an Open Access article licensed under the terms of the } \\
\text { Creative Commons Attribution-NonCommercial 3.0 Un- } \\
\text { ported license (CC BY-NC) (www.karger.com/OA-license), } \\
\text { applicable to the online version of the article only. Distribu- } \\
\text { tion permitted for non-commercial purposes only. }\end{array}$
\end{tabular}

Dr. Mansur Doğan

Department of Otolaryngology, Cumhuriyet University School of Medicine TR-58140 Sivas (Turkey)

E-Mail mansurdogan@ hotmail.com 
rangement of the TMJ is defined as a disturbance in the normal anatomic relationship between the disk and the condyle, which may cause pain and dysfunction $[5,6]$. Up to $25 \%$ of the entire world population has internal derangement of the TMJ, and they are usually treated with nonsurgical methods. When these methods are unsuccessful, the disorder is often managed by surgery [3].

Reversible, conservative therapy such as cognitive behavioral therapy, physical therapy, pharmacological therapy, and intraoral appliances should be considered for the first-line management of TMD [5]. Splint therapy is performed using various types of stabilization, anterior positioning, or bite plane appliances [6]. However, current concepts reveal that TMJ pain and dysfunction strongly depend on the adaptive capacity of patients rather than the position of the disk [6]. Moreover, numerous forms of physical therapy intervention, including ultrasound and transcutaneous electrical nerve stimulation, can be potentially effective in the management of TMD to reduce pain and improve the mandibular range of motion [7].

Despite the fact that drugs are used to treat a myriad of problems such as TMD, bruxism (teeth grinding), chronic tension headaches, and migraines, they still have numerous side effects, which have caused the authors to try to find safe, new therapy modalities such as ozone therapy. Ozone therapy is a frequently applied physiotherapy method [8]. The worldwide use of ozone for treating many diseases, including cancer, HIV, and rheumatoid arthritis, has been growing rapidly $[8,9]$. As ozone is very destructive to viruses, bacteria, and fungi, all suspected causative organisms for rheumatoid arthritis, its proper use can only be beneficial for the arthritic patients. Ozone has been used to promote hemostasis, enhance local oxygen supply, and inhibit bacterial proliferation $[8,9]$. Hence, ozone has become popular in medicine and dentistry and is now used in the treatment of knee disorders; however, to our knowledge, no study has used bio-oxidative ozone to treat pain due to TMD. Therefore, the objective of this study was to investigate the efficacy test of ozone therapy compared to drug treatment in patients with painful TMD.

\section{Subjects and Methods}

Selection of Patients

The Institutional Ethics Committee approved the study and informed consent was obtained from all patients. Based on clinical and radiographic examinations, 63 patients were selected from among consecutive patients who requested a consultation with the
Department of Otolaryngology due to complaints of TMJ pain or dysfunction. Inclusion criterion was a major complaint of acute pain in the joint on at least one side. Exclusion criteria were patients with degenerative joint diseases such as osteoarthritis, rheumatoid arthritis, and gout causing TMJ dysfunction.

A subjective pain evaluation was done by showing each patient a 10 -cm-long, visual analogue scale (VAS; 0 for pain free and 10 for maximum pain). The maximum voluntary interincisal mouth opening (MMO) of the patients was measured in millimeters using a scale, and the duration of the symptoms was recorded as well. The presence of clicking sounds was detected by bilateral palpation of the TMJ, with the left index finger positioned on the right TMJ and the right index finger on the left TMJ in the preauricular area, anterior to the auricular tragus. All measurements and recordings were performed by the same researcher (D.Ö.D.) who was blinded to the groups.

Patients were randomly allocated into 2 groups: the ozone group $(\mathrm{n}=33)$ and the medication group $(\mathrm{n}=30)$. The sealed envelope technique was used for randomization. Pre- and posttreatment clinical assessments were performed by a single clinician (M.D.) for signs and symptoms of TMD that included pain, mouth opening, joint noises, and jaw deviation. The baseline data were recorded at an initial examination before the start of treatment. The outcome data were collected immediately upon the termination of the last treatment. An oxygen activation generator (OzonytronX, Manufacturer Biozonix $\mathrm{GmbH}$, Munich, Germany) was used for the application of highfrequency, bio-oxidative therapy, which uses high-frequency and voltage power. Activated oxygen (ozone) concentration of $30 \%$ that could be adjusted to 5 levels via current strength was used. For the application of high-frequency, bio-oxidative therapy, omega probes were used for both joint sides. Inside the glass probe, which is formed by a double glass camera, there is a mixture of noble gasses that conducts and emits electromagnetic energy. When the tip of the probe comes into contact with the body, it emits energy around the treated area and splits environmental, diatomic oxygen into singular atomic oxygen and ozone. Strong, high-frequency stimuli are suitable for deep tissue stimulation, which reaches and affects subcutaneous, deep tissue with discharges from the omega probe. Ozone therapy was applied to the joints of 33 patients 3 times per week for $10 \mathrm{~min}$. Patients did not feel pain, although they felt a mild increase in temperature in the respective region during the therapy.

In the medication group, all 30 patients received the same medications: ketoprofen $150 \mathrm{mg}$ tablet twice a day $(300 \mathrm{mg}$ /day; BiProfenid 150-mg tablet, Sanofi Aventis) and 1 thiocolchicoside 8-mg capsule twice a day $(16 \mathrm{mg} /$ day; Muscoril 8-mg capsule, Sanofi Aventis) for 7 days.

\section{Statistical Analysis}

The estimated number of participants was 33 for each group, with an $\alpha$ error of 0.05 and a power of 0.9 in the 2 -sided test. SPSS (version 14; Chicago, Ill., USA) programs were used to perform statistical analysis. While all of the 63 patients in the ozone group completed the study, 3 patients in the medication group were excluded due to lack of cooperation. The ozone group included 5 males and 28 females, and the medication group included 4 males and $26 \mathrm{fe}-$ males. Data are presented as means \pm standard deviations. Demographic data were analyzed using the Mann-Whitney U test and VAS scores, and the MMO values were analyzed using the KolmogorovSmirnov test and compared between groups using an independent $t$ test. A paired-sample $t$ test was used to analyze intragroup baseline VAS and MMO data. $p$ values $<0.05$ were considered significant. 


\section{Results}

The demographics of all patients are given in table 1 , and there were no differences between the groups. The MMO value for the ozone group during the pretreatment period was $46.51 \pm 8.2 \mathrm{~mm}$, and it immediately increased to 48.78 $\pm 7.5 \mathrm{~mm}$ after 1 week of ozone therapy, which was statistically significant $(\mathrm{p}<0.05)$. The MMO values for the medication group were $46.30 \pm 6.0 \mathrm{~mm}$ before and $49.6 \pm 5.7 \mathrm{~mm}$ after treatment of 1 week. The difference was also statistically significant. No differences were found in pre- and posttreatment MMO values between the ozone and medication groups (table 2).

The maximum increase in mouth opening was $9 \mathrm{~mm}$ in 2 patients in the ozone group. There was no difference in terms of mouth opening in 11 patients in the ozone group and in 12 patients in the medication group. However, 22 patients in the ozone group had a $4.09-\mathrm{mm}$ increase in mouth opening, and 18 patients in the medication group had a $1.11-\mathrm{mm}$ increase in mouth opening from the medial line of maxillary incisors to the medial line of mandibular incisors.

The mean pretreatment VAS pain score was 6.35 and that of the posttreatment period was 3.06 after 1 week $(\mathrm{p}<0.05)$. The mean VAS pain score was 6.96 during the pretreatment period, and the posttreatment period pain scores decreased to 5.00 after 1 week $(\mathrm{p}<0.05)$. In the ozone group, 29 patients (87.8\%) showed a gradual decrease in the VAS pain score compared to pretreatment values. In the medication group, 24 patients (80\%) showed a significant decrease in VAS pain scores during the follow-up period. There were no differences about pretreatment VAS scores between the groups. Posttreatment VAS scores in the ozone group were significantly lower than in the medication group $(\mathrm{p}<0.05$; table 2$)$.

No change was found between intragroup pre- and posttreatment VAS scores in 3 patients in the ozone group and in 4 patients in the medication group. However, 1 patient in the ozone group and 2 patients in the medication group had an increase in VAS score.

Four patients in the ozone group did not complain of any pain after the treatment. Three patients in the medication group had a VAS score of 1 , and no patient had complete relief.

\section{Discussion}

Ozone therapy was more effective than medication therapy in patients with high pain scores for increasing MMO values and relieving pain. Hence, ozone therapy was an effective treatment for TMJ pain.

Ozone therapy in TMJ pain is a new treatment modality. There are few studies on this issue [10], and in our literature review, we could not find any other study that was similar to ours. Ozone therapy was accepted as an alternative medicine therapy in the USA from 1880 to 1932 . To date, ozone therapy has been a recognized treatment modality in 16 countries [11]. There are several ozone therapy modalities and bio-oxidative therapy methods. All of these methods have been improved by researchers over the years [12].

There have been several ozone application areas in dentistry such as the management of incipient caries, the

Table 1. Demographic characteristics

\begin{tabular}{lccl}
\hline & $\begin{array}{c}\text { Group 1 } \\
(\mathrm{n}=33)\end{array}$ & $\begin{array}{c}\text { Group 2 } \\
(\mathrm{n}=30)\end{array}$ & $\mathrm{p}$ \\
\hline Age, years & $32.7 \pm 9.2$ & $34.7 \pm 10.0$ & 0.474 \\
Height, cm & $163.7 \pm 4.5$ & $164.6 \pm 8.1$ & 0.825 \\
Weight, kg & $69.3 \pm 10.9$ & $73.3 \pm 12.0$ & 0.176 \\
\hline
\end{tabular}

Group 1 = Ozone group; group 2 = medication group .

Table 2. MMO and VAS data

\begin{tabular}{|c|c|c|c|c|c|c|}
\hline & \multicolumn{3}{|l|}{$\mathrm{MMO}$} & \multicolumn{3}{|c|}{ VAS score } \\
\hline & $\begin{array}{l}\text { group 1 } \\
(\mathrm{n}=33)\end{array}$ & $\begin{array}{l}\text { group } 2 \\
(\mathrm{n}=30)\end{array}$ & $\mathrm{p}$ & group 1 & group 2 & $\mathrm{p}$ \\
\hline Pretreatment $\mathrm{MMO}, \mathrm{mm}$ & $46.5 \pm 8.2$ & $46.3 \pm 6.0$ & 0.907 & $6.3 \pm 2.1$ & $6.9 \pm 1.4$ & 0.199 \\
\hline Posttreatment MMO, mm & $48.7 \pm 7.5$ & $46.9 \pm 5.7$ & 0.289 & $3.0 \pm 2.2$ & $5.0 \pm 1.5$ & $0.000^{\mathrm{a}}$ \\
\hline $\mathrm{p}$ & $0.004^{\mathrm{b}}$ & $0.010^{\mathrm{b}}$ & & $0.000^{\mathrm{b}}$ & $0.000^{\mathrm{b}}$ & \\
\hline
\end{tabular}


management of open or root caries, periodontitis, periimplantitis, oral microbiology, endodontics, prosthodontics, oral and maxillofacial surgery, and dental surgeries $[13,14]$. Therapeutic modalities for the administration of intraoral ozone include irrigation with ozonized water, gas injection, topical application of ozonized oil, and gas insufflation of periodontal pockets. Some of the injection protocols are intraosseous injection of an ozone-oxygen gas mixture locally into the alveolus, subgingivally and intramuscularly into the inferior alveolar nerve area, and into the pterygoid space. Irrigation with ozonized water is also utilized for oral infections including stomatitis, herpetic lesions, and subgingival, periodontal infections. Insufflation techniques with ozone gas are generally utilized for caries, periodontal infections, and endodontic treatment. Extraoral, therapeutic protocols include nasal and ear insufflation, TMJ injections, trigger point injections, and craniofacial, lymphatic injections [15].

As mentioned before, only one previous study has explored ozone for the treatment of temporomandibular pain. Daif [10] injected intra-articular ozone to the TMJ, and the results of his study demonstrated that $87 \%$ of the patients who received ozone gas injections into the superior joint space $(n=26)$ either completely recovered $(37 \%$; $\mathrm{n}=11)$ or improved $(50 \% ; \mathrm{n}=15)$. In the second group, $33 \%$ of the patients who were treated with nonsteroidal, anti-inflammatory drugs and muscle relaxants $(n=10)$ showed an improvement only in their clinical dysfunction indexes. On the basis of his findings, Daif [10] concluded that intra-articular ozone gas injection was a promising new treatment modality for the internal derangement of
TMJ, but that further clinical and experimental studies were required to provide direct evidence for its mechanism of action and to substantiate their results. Despite the results of this study being similar to ours, our study differs from that of Daif in the method of applying the ozone to the TMJ. Our method is not invasive and is therefore easier than that of Daif.

Possibly, ozone causes the joint to heal much more quickly than traditional therapy. The probable explanation is that ozone is a highly reactive molecule, and when injected or administered into a joint capsule, it is able to stimulate the fibroblastic joint-repairing abilities. It may also reduce inflammation and promote new cartilage growth. When ozone molecules split into single oxygen atoms, they can react when in contact with a contaminant. Ozone is so reactive that it never fails to initiate this reactive activity [ $8-10]$. It has also been shown that ozone can reduce airborne infections $[16,17]$. The probable mechanism is due to a single oxygen atom oxidizing the contaminants. During the process of this reaction, it destroys the contaminants that come into contact by changing their physical properties, resulting in the contaminants no longer being toxic or able to reproduce [17].

In conclusion, ozone therapy was an effective method for the treatment of pain due to TMD, and it was safe and more effective than medication therapy.

\section{Disclosure Statement}

The authors have no conflicts of interest to disclose.

\section{References}

1 Cairns BE: Pathophysiology of TMD pain basic mechanisms and their implications for pharmacotherapy. J Oral Rehabil 2010;37: 391-410.

2 Okeson JP: Management of Temporomandibular Disorders and Occlusion, ed 6. St Louis, Mosby, 2008, pp 176-189, 413.

-3 Barkin S, Weinberg S: Internal derangements of the TMJ: the role of arthroscopic surgery and arthrocentesis. J Can Dent Assoc 2000;69: 199-203.

4 Lamontagne P, Al-Tarakemah Y, Honkala E: Relationship between the preferred chewing side and the angulation of anterior tooth guidance. Med Princ Pract 2013;22:545-549.

5 Durham J: Temporomandibular disorders (TMD): an overview. Oral Surg 2008;1:60-68.

6 Klasser GD, Greene CS: Oral appliances in the management of temporomandibular disorders. Oral Surg Oral Med Oral Pathol Oral Radiol Endod 2009;107:212-223.
7 McNeely ML, Armijo Olivo S, Magee DJ: A systematic review of the effectiveness of physical therapy interventions for temporomandibular disorders. Phys Ther 2006;86:710-725.

-8 Rahimi-Movaghar V: The major efficient mechanisms of ozone therapy are obtained in intradiscal procedures. Pain Physician 2012; 15:E1007-E1008.

-9 Bocci V, Zanardi I, Travagli V: Has oxygenozone therapy a future in medicine? J Exp Integr Med 2011;1:5-11.

10 Daif ET: Role of intra-articular ozone gas injection in the management of internal derangement of the temporomandibular joint. Oral Surg Oral Med Oral Pathol Oral Radiol 2012;113:10-14.

11 Bocci V: Ozone as Janus: this controversial gas can be either toxic or medically useful. Mediators Inflamm 2004;13:3.

12 Gupta G, Mansi B: Ozone therapy in periodontics. J Med Life 2012;5:59-67.
13 Grootveld M, Baysan A, Sidiiqui N, et al: History of the clinical applications of ozone; in Lynch E (ed): Ozone: The Revolution in Dentistry. London, Quintessence, 2004, pp 23-30.

14 Baysan A, Lynch E: Antimicrobial effects of ozone on caries; in Lynch E (ed): Ozone: The Revolution in Dentistry. London, Quintessence, 2004, pp 165-172.

15 Rothchild JA, Harris RE, Mollica PJ: Current concepts of oxygen ozone therapy for dentistry in the United States. Int J Ozone Ther 2010; 9:105-108.

16 Jakab GJ, Hmieleski RR: Reduction of influenza virus pathogenesis by exposure to 0.5 ppm ozone. J Toxicol Environ Health 1988; 23:455-472.

17 Wolcott JA, Zee YC, Osebold JW: Exposure to ozone reduces influenza disease severity and alters distribution of influenza viral antigens in murine lungs. Appl Environ Microbiol 1982;44:723-731. 